\title{
Nutrition and Hearing Loss
}

\author{
Michael AB Naafs* \\ Naafs International Health Consultancy, Europe
}

Submission: July 22, 2018; Published: July 25, 2018

*Corresponding author: Michael AB Naafs, Internist-endocrinologist with a long clinical career in internal medicine and endocrinology, Naafs International Health Consultancy, Dutch, Europe, Email: naafs.healthconsultancy@gmail.com

Abstract

Recent research showed an association between nutritional iodine deficiency and hearing loss. Little is known about iodine deficiency in relation to auditory function. Even more controversial is the role of vitamins, antioxidant and mineral supplements in preventing or reducing hearing loss. The advent of nutrigenomics is expected to build on new research in the field of "nutritional hearing loss".

\section{Introduction}

Recently, researchers reported that U.S. teens with the lowest levels of urinary iodine were five times more likely to have hearing loss associated with speech comprehension than their peers with higher iodine levels [1]. Iodine deficiency affects an estimated 241 million school-aged children in the world. Little is known about iodine deficiency in relation to auditory function, except for the fact that deaf-mutism is one of the features of cretinism [2]. Hearing loss is the fourth-leading cause of disability worldwide. About $80 \%$ of people with hearing loss live in low-and middle-income countries. John Hopkin's researchers studied 2200 children in Nepal, who were undernourished during their preschool years. They found that those who were undernourished in their preschool years were about twice as likely to have hearing loss 16 years later than those who were better nourished as young children [3]. Previous studies have linked deficiencies of micronutrients, including vitamin A and zinc to hearing impairment [4]. although this was believed to be related to an increased incidence of otitis media in malnutrition [5].

Of course, it is far more difficult to quantify the quantity and quality of foods consumed over a long period of time, than it is to quantify hearing loss at a moment in time. In high-income countries, large population studies have reported protective risk ratios against hearing loss with higher dietary intakes of fish, long chain polyunsaturated fatty acids (PUFAs) folate, beta-carotene and vitamins A,E, and C [6]. Heavy metals have been implicated in hearing loss [7]. All these studies add to the developing story that adequate and balanced nutrition during pregnancy, infancy may reduce hearing loss globally and across the life-span. Accurate, faster and less costly studies for measuring diet, status of micronutrients, and hearing are needed to investigate the role of nutrition in hearing loss, both in under-and over-nutrition. In this mini-review the available evidence for the role of nutri tion in hearing loss will be discussed. Nutrition and tinnitus is beyond the scope of this review.

\section{Iodine Deficiency}

The occurrence of congenital deafness, mutism and goiter unassociated with cretinism or mental retardation in euthyroid patients is known as Pender's syndrome. It is estimated that $4-10 \%$ of children with congenital deafness suffer from this condition [8]. The perceptive hearing loss is considered to be present at birth although it is frequently not recognized for years. The goiter becomes only apparent in the prepubertal years. The cause of the hearing defect is a congenital bilateral malformation of the cochlea of the Mendini type. The thyroid defect has been shown to be a partial defect in iodine organocation leading to the underproduction of thyroxine, progressing to a nodular goiter. The autosomal recessive mutant gene is responsible for both the deafness and goiter [8]. Hearing impairment was also reported in thyroid hormone resistance syndromes caused by mutations in the beta-thyroid hormone receptor gene (beta TR gene).Because of its otogenic distribution in the cochlea the beta-TR may have a pivotal role in the development of hearing impairment in thyroid hormone resistance syndromes [9]. Hearing loss in thyroid disease is in addition to congenital hypothyroidism most commonly associated with hypothyroidism due to autoimmune disorders, as e.g. Hashimoto's disease [10].

Hearing loss associated with Graves'disease (hyperthyroidism) and or propylthiouracil treatment is less commonly reported. Taken together it is not surprisingly the role of iodine in hearing loss has been investigated further. Van den Briel et al [11]. investigated 197 school children in an iodine-deficient area in northern Benin. In this randomized placebo-controlled intervention trial with an observation period of 11 months a to- 
tal of 97 children received an oral dose of iodized oil containing $540 \mathrm{mg} / \mathrm{l}$, while 100 children received a placebo. After 3-4 months supplementation, the whole population began to have access to iodized salt. Urinary iodine was measured at the beginning and the end of the study, as well as thyroglobulin (TG) concentrations. In this mildly iodine-deficient child population children with higher TG concentrations had significantly higher hearing thresholds in the higher frequency range $(>2000 \mathrm{~Hz})$ than children with lower serum TG concentrations. Moreover, children with lower hearing thresholds performed significantly better on the mental tests used. The authors concluded that adequate iodine intake through salt iodization programs and other means are crucial [12]. Males Bootstrap and Mackenzie reviewed the literature regarding the role of iodine and hypothyroidism on the auditory system [2].

They found that ear development and hearing function depend on thyroid hormones, involving multiple pathways. Conductive as well as sensorineural hearing loss has been found in animals that were rendered hypothyroidism. In humans, auditory impairment is reported more frequently related to congenital than to acquired hypothyroidism. The critical period for thyroid function-related hearing maturation is in the first and second trimesters of pregnancy. Most studies point to an association and evidence from good randomized controlled trials (RCTs) is lacking [2]. The recently reported association between iodine deficiency and hearing loss in U.S. teens shows "nutritional hearing loss" is not a problem of third world countries alone [1]. This has important public health implications. The major dietary sources of iodine are iodized salt, seafood, dairy and grains. The iodine content of vegetarian and vegan diets may be inadequate. Pregnant young women using these diets should therefore use iodine supplements [13].

\section{Vitamins, Minerals and Antioxidants}

On the internet a plethora of vitamin supplements, antioxidants and minerals are offered to prevent or reduce age-related and noise-related hearing loss. Is there any scientific base for these claims? Numerous animal studies have shown the otoprotective effects of free radical scavengers, and the antioxidant properties of vitamin C,E and beta-carotene have been demonstrated to protect from inner ear damage caused by aminoglycosides, cisplatin, acoustic trauma, noise exposure and presbyacusis $[14,15]$. However, the limited number of human studies have yielded conflicting results. The Health Professional Follow-up Study enrolled 51.529 male participants who were 41-75 years of age at baseline in 1986.During a 20 year follow-up participants filled out yearly questionnaires about diet, medical history and medication use. Of the 33.884 men who responded to the long form questionnaire,7092 (20,3\%) reported a diagnosis of hearing loss. Overall the study found no prospective association between vitamin C,E, beta-carotene,B12 or folate intake and incident hearing loss in men 60 years and older [16].
The Australian Blue Mountain Study enrolled 2956 participants aged 50 plus at baseline that have been followed from 1979-9 to 2002-4. Dietary data were collected in a semi-quantitative food frequency questionnaire. Intakes of alpha-carotene, beta-carotene, beta cryptoxanthin. lutein, zeaxanthin, lycopene, vitamins A,C,E, Iron and zinc were calculated. The authors concluded dietary vitamin A and vitamin E were significantly associated with the prevalence of hearing loss but not with the incidence of hearing loss. Dietary antioxidant use did not increase the risk of hearing loss [17]. A NHANES cohort (2001-2004) was studied by Choi et al for the associations between intake of antioxidant vitamins (daily beta-carotene and vitamins $\mathrm{C}$ and $\mathrm{E}$ and magnesium) and hearing thresholds and explored their joint effect in U.S. adults. A cohort from 2592 participants, aged 20-69 years, were studied.in the NHANES 2001-2004 cohort. Higher intakes of antioxidants and magnesium, individually and in combination appeared to be associated with a lower risk of hearing loss.

This cross-sectional finding does not allow for the conclusion that antioxidants and magnesium have a causal protective effect on hearing loss [18]. The Conservation of Hearing Study examined risk factors for hearing loss among participants in the Nurses Health Study 2,an ongoing cohort of 116.430 female registered nurses in the U.S. aged 25-42 year at cohort inception in 1989 [6]. Participants have been followed by biennial mailed questionnaires asking for diet information, life style, incident disease, and various health outcomes.After 1.084 .598 person-years of follow-up 12.789 cases of hearing loss were reported in this white women study. Higher intakes of carotenoids, especially of beta-carotene and beta-cryptoxanthin were statistically associated with a lower risk of hearing loss. Higher vitamin C levels from supplements were associated with a higher risk of hearing loss. Higher folate levels tended to be associated with lower risk. No significant associations were observed between intake of vitamin A, other carotenoids, or vitamin $\mathrm{E}$ and risk of hearing loss in these women [6].

Ibrahim et al [19] reviewed the evidence for an effect of adjuvant vitamin/mineral therapy for sudden sensorineural hearing loss but could not find convincing evidence as the vitamins were combined together or were used in combination with selenium. From 446 manuscripts only 3 were eligible and were included with 279 patients following Cochrane bias criteria. So, these questionnaire studies will not give the answer if vitamins ,antioxidants and minerals are beneficial in preventing or reducing hearing loss. Multivitamin/multimineral supplements are widely used in the US ,sometimes containing 20 different of each per supplement. This reduces deficiencies in micronutrient in take, but has also the potential for exceeding tolerable upper intake levels. The advent of nutrigenomics and the enhanced ability to directly study the interaction between nutrition and genetic variants and expression will allow for more targeted studies in the field of personalized nutrition. This will also be the case 
in the field of "nutritional hearing loss". The ongoing Cocoa and Multivitamin Outcomes Study (COSMOS) is expected to build on this research and provide additional insights in these areas [20].

\section{Conclusion}

Recent research showed an association between iodine deficiency and hearing loss $[1,3]$. Although the role of thyroid hormone in auditory development is fairly well established in congenital hypothyroidism and thyroid hormone resistance syndromes, little is known about iodine deficiency in relation to auditory function Population questionnaire studies did not resolve this problem. The role of vitamins, antioxidants and minerals in "nutritional hearing loss" is even more controversial. The advent of nutrigenomics and the ability to directly study the interaction between nutrition and genetic variants will allow for more targeted studies, also in the field of "nutritional hearing loss".

\section{References}

1. Scinicriello F, Buser MC (2018) Association of Iodine Deficiency with Hearing Impairment in U.S. Adolescents Aged 12-19 Years: Analysis of NHANES 2007-2010 Data. JAMA Otolaryngol. Head Neck Surg. Research Letter June 7.

2. Melse A, Mackenzie I (2013) Iodine deficiency, thyroid function and hearing deficit: A review. Nutr Res Rev 26(2): 110-117.

3. Emmett SD, Schmitz J, Karna SL, Khatry SK, Wu L, et al. (2018) Early childhood undernutrition increases risk of hearing loss in young adulthood in rural Nepal. Am J Clin Nutr 107(2): 268-277.

4. Etemraid MA, Mackenzie IJ, Fraser WD (2009) Nutritional factors in the pathogenesis of ear disease in children :a systematic review. Am Trop Peadiatr 29(2): 85-99.

5. Monasta L, Ronfani L, Marchetti F, Montico M, Vecchi Brumatti L, et al. (2012) Burden of disease caused by otitis media: systemic review and global estimates. Plos One 7(4): 7e36226.

6. Curhan SG, Stankovic KM, Eavey RD, Wang M, Stampfer MJ, et al. (2015) Carotenoids, vitamin A, vitamin Vitamin E, and folate and risk of selfreported hearing loss in women. Am J Clin Nutr 102(5): 1167-75.

7. Shargorodsky J, Curhan SG, Henderson E, Eavey R, Curhan GC (2011) Heavy metals exposure and hearing loss in U.S. adolescents. Arch. Otolaryngol. Head Neck Surg 137(12): 1183 -1189.
8. Pendred Syndrome (2017) National Institute on Deafness and Other Communication Disorders. syndrome; last updated March 6.

9. Brucker Davis F, Skarulis MC, Pikus A, Ishizawar D, Mastroianni MA, et al. (1996) Prevalence and mechanisms of hearing loss in patients with resistance to thyroid hormone. J Clin Endocrinol Metab 81(8): 27682772.

10. Arduc A, Isık S, Allusoglu S, Iriz A, Dogan BA, et al. (2015) Evaluation of hearing functions in patients with euthyroid Hashimoto's thyroiditis. Endocrine 50(3): 708-714.

11. Berker D, Karabulut H, Isik S, Tutuncu Y, Ozuguz U, et al. (2012) Evaluation of hearing loss in patients with Graves'disease. Endocrine 41(1): 116-121.

12. Van den Briel T, West CE, Hautvast JG (2001) Mild iodine deficiency is associated with elevated hearing thresholds in children in Benin. Eur J Clin Nutr 55(9): 763-768.

13. Fields C, Barak J (2009) Iodine deficiency in Vegetarian and Vegan Diets: Evidence-Based Review of the Worlds Literature on Iodine Content in Vegetarian Diets. Comprehensive Handbook of Iodine 2(2005): 37-46.

14. Takumida M, Anniko M (2005) Radical scavengers: A remedy for presbyacusis; A pilot study. Acta Otolaryngol 125(12): 1290-1295.

15. Le Prell CG, Hughes LF, Miller JM (2007) Free radical scavengers vitamins $\mathrm{A}, \mathrm{C}$ and $\mathrm{E}$ plus magnesium reduce noise trauma. Free Radic. Biol. Med 42(9): 1454-1463.

16. Shargorodsky J, Curhan SG, Eavey R, Curhan GC (2010) A prospective study of vitamin intake and the risk of hearing loss in men. Otolaryngol. Head Neck Surg 142(2): 231-236.

17. Gopinath B, FloodC VM, McMahon M, Burlutsky G, Spankovich C, et al. (2011) Dietary antioxidant intake is associated with the prevalence but not incidence of age-related hearing loss. J Nutr Health Aging 15(10): 896-900.

18. Choi YH, Miller JM, Tucker KL, Hu H, Park SK (2014) Antioxidant, vitamins and magnesium and the risk of hearing loss in the U.S. general population. Am J Clin Nutr 99(1): 148-155.

19. Ibrahim L, Zeitouni A, da Silva SD (2018) Effect of Antioxidant Vitamins as Adjuvant Therapy for Sudden Sensorineural Hearing Loss: Systematic Review Study. Audiol Neurotol 23(1): 1-7.

20. Blumberg JB, Bailey R, Sesso HD, Ulrich C (2018) The Evolving Role of Multivitamin/Multimineral Supplement Use among Adults in the Age of Personalized Nutrition. Nutrients 10(2): 248.

\section{Your next submission with Juniper Publishers will reach you the below assets}

- Quality Editorial service

- Swift Peer Review

- Reprints availability

- E-prints Service

- Manuscript Podcast for convenient understanding

- Global attainment for your research

- Manuscript accessibility in different formats

( Pdf, E-pub, Full Text, Audio)

- Unceasing customer service

Track the below URL for one-step submission

https://juniperpublishers.com/online-submission.php 